\title{
Biodegradation of porous versus non-porous poly(L-lactic acid) films
}

\author{
K. H. LAM, P. NIEUWENHUIS, I. MOLENAAR, \\ Department of Histology and Cell Biology, Section Biomaterials, University of Groningen, \\ Oostersingel 69-1, 9713 EZ Groningen, The Netherlands
}

H. ESSELBRUGGE, J. FEIJEN, P. J. DIJKSTRA

Department of Chemical Technology, University of Twente, PO Box 217, 7500 AE Enschede, The Netherlands

J. M. SCHAKENRAAD*

Biomedical Technology Centre, University of Groningen, Oostersingel 59, Building 25, 9713 EZ Groningen, The Netherlands

The influence of porosity on the degradation rate of poly (L-lactic acid) (PLLA) films was investigated in vitro and in vivo. Non-porous, porous and "combi" (porous with a non-porous layer) PLLA films were used. Changes in $\mathrm{Mw}, \mathrm{Mn}$, polydispersity $(\mathrm{Mw} / \mathrm{Mn})$ ratio, melting temperature $\left(T_{\mathrm{m}}\right)$, heat of fusion, tensile strength, E-modulus, mass and the remaining surface area of cross-sections of the PLLA films were measured. In general, during the degradation process, the porous film has the highest $\mathrm{Mw}, \mathrm{Mn}, \mathrm{Mw} / \mathrm{Mn}$ ratio and $T_{\mathrm{m}}$, while the nonporous film has the lowest. In contrast, the highest heat of fusion values were observed for the non-porous film, indicating the presence of relatively smaller molecules forming crystalline domains more easily. The tensile strength and E-modulus of the non-porous film decrease faster than those of the porous and the combi film. None of the three types of films showed massive mass loss in vitro nor a significant decrease in remaining polymer surface area in light microscopical sections in vitro and in vivo. Heavy surface erosion of the non-porous layer of the combi film was observed after 180 days, turning the combi film into a porous film. This is also indicated by the changes in tensile strength, $\mathrm{Mw}, \mathrm{Mw} / \mathrm{Mn}, T_{\mathrm{m}}$ and heat of fusion as a function of time. It is concluded that non-porous PLLA degrades faster than porous PLLA. Thus, in our model, porosity is an important determinant of the degradation rate of PLLA films.

\section{Introduction}

Many factors determine the inflammatory response to a polymer (either synthetic or natural) used as a biomaterial: chemical composition [1], surface free energy [1], surface charge [2], porosity [3], roughness of the surface [4], shape [5], implantation site [6], toxicity [7], rate of degradation [8] and degradation products $[7,8]$.

The rate of degradation is an important factor, determining the nature and intensity of the inflammatory response and therefore the biocompatibility of an implanted polymer material. Upon degradation, fragments, oligomers and monomers are released. In addition, catalysts and solvents used for the polymerization and purification of the polymer may also be released. Moreover, the morphology (shape, porosity) of the implanted polymer may change during degradation. The degradation products released, and the change of shape can provoke a renewed acute inflammatory response, irrespective of whether the implant was already surrounded by a fibrous connective tissue layer or whether layers of macrophages and/or giant cells were localized between the implant and fibrous connective tissue layers [9].

Controlling the rate of degradation can contribute to the reduction of the intensity of the inflammatory response and consequently improve biocompatibility. Understanding the role of the factors which determine this degradation rate will contribute to its control. An important factor is the presence of hydrolysable bonds in the polymer backbone $[10,11]$. In addition, when a biomaterial has to perform its function in a physiological environment such as the human body, the wettability of these polymers with hydrolysable bonds is also an important factor [11]. Another factor determining the degradation rate may be the presence of enzymes. It has been demonstrated that enzymes can enhance degradation under specific circumstances in vitro [12-14]. However, the exact role of enzymes in the degradation process of polymers in vivo is still unclear.

Morphology (porosity) is also one of the parameters which might influence the degradation rate of polymer films. It was observed [15-17] that the core of poly(L-

* To whom correspondence should be addressed. 
lactic acid), poly(glycolic acid) and their copolymers degraded first, forming a semi-permeable layer with a higher molecular weight and crystallinity around the degrading core. This layer prevents a large part of the oligomers (resulting from the degradation process in the core) to be released. As a consequence, the chemical reactive endgroups of these oligomers enhance the degradation in the core by an autocatalytic process. It is not known whether this degradation behaviour remains the same for a polymer film which has a morphology with a relatively large surface to volume ratio, such as the walls between the pores of a porous polymer film.

To study the influence of porosity on the degradation rate in more detail, poly(L-lactic acid) (PLLA) films with different porosity were cast. PLLA is a wellcharacterized degradable polymer already used clinically, e.g. as a copolymer in sutures. Extensive research is being done for other uses of PLLA $[18,19]$. We have chosen PLLA with the lowest molecular weight possible for casting films for possible clinical use such as parodontal filters. We are also particularly interested in the end stages of the degradation and resorption processes of these films.

Investigating the role of porosity as a factor determining the rate of degradation of PLLA films makes it necessary to characterize the polymer and measure its rate of degradation in vivo and in vitro. Monitoring the change in the chemical (Mw, Mn) $[20,21]$ and physical properties (melting temperature, heat of fusion) of PLLA as it degrades, can contribute to the understanding of the degradation process. Testing of the mechanical properties (load at break/tensile strength, E-modulus) [22] gives an indication of the loss of the mechanical properties, possibly making it unsuitable for some applications. The determination of the mass of the remaining polymer (film) by gravimetrical methods and the surface area of the cross section of the remaining polymer in lightmicroscopical sections by morphometry, provide information on the resorption process after the initial stages of the degradation process.

\section{Materials and methods}

\subsection{Poly (L-lactic acid) films}

Poly(L-lactic acid) (PLLA) films were cast from PLLA with a reported Mv of 50000 (Purac Biochem B.V., Gorinchem, The Netherlands) [23]. The parameters of this initial PLLA, determined using gel permeation chromatography and differential scanning calorimetry as described in the following sections, were as follows: $\mathrm{Mw}=99000, \quad \mathrm{Mn}=44500$, polydispersity ratio $(\mathrm{Mw} / \mathrm{Mn})=2.2, T_{\mathrm{m}}=183.2^{\circ} \mathrm{C}$ and heat of fusion $=64.0 \mathrm{~J} / \mathrm{g}$. Three types of film were cast: a nonporous type, a porous type and a "combi" type (porous with a non-porous layer on one side).

The non-porous film was made using a $20 \% \mathrm{w} / \mathrm{w}$ PLLA solution in chloroform (pro analysi, Merck, Germany) at room temperature. Prior to casting, the solution was not stirred for an hour to let the larger air bubbles escape. The surface of the glass plate on which the films were cast was cleaned with ethanol (technical grade, distilled $1 \mathrm{x}$ ). A uniform thickness was achieved by using a doctor's blade. The distance between the blade and the glass plate was $400 \mu \mathrm{m}$. After casting, the chloroform was evaporated in a continuous flow of dry $\mathrm{N}_{2}$. The films were removed from the glass plate after $20 \mathrm{~h}$ and washed in ethanol (pro analysi, Merck, Germany) for $16 \mathrm{~h}$. After drying in air, the films were further dried in vacuum over $\mathrm{P}_{2} \mathrm{O}_{5}$ at $40{ }^{\circ} \mathrm{C}$.

The porous films were made using a $5 \% \mathrm{w} / \mathrm{w}$ PLLA solution in chloroform at room temperature. Subsequently, $40 \mathrm{~g}$ sodium citrate (Fluka Chemie, The Netherlands), which was sieved (grain diameter $<36 \mu \mathrm{m}$ ), was added in portions of $10 \mathrm{~g}$ to approximately $70 \mathrm{ml} \mathrm{PLLA} /$ chloroform solution in order to achieve a film having a pore volume of approximately $80 \%$. The salt grains were dispersed in a low capacity ultrasonic bath in order to prevent heating of the solution. Air bubbles were eliminated simultaneously by this procedure. The distance between the blade and the glass plate was $750 \mu \mathrm{m}$, controlling the thickness of the solution cast. The films were then dried as described above. After drying, the films were washed in demineralized water for $16 \mathrm{~h}$ in order to remove the salt and subsequently washed for $16 \mathrm{~h}$ in ethanol. The drying procedure which followed was the same as described for the non-porous film.

The combi films were made by casting a non-porous film as described above on a glass plate first. Subsequently, over this non-porous part, a porous part was cast as described for the porous film. The distance between the blade and the glass plate was $750 \mu \mathrm{m}$. The procedures for washing and drying of these films were as described for the porous films.

The final thickness of the films was determined with scanning electron microscopy (SEM). Strips of 15 $\times 2 \mathrm{~mm}$ were used for in vivo procedures and strips of $40 \times 2 \mathrm{~mm}$ were used for in vitro procedures, taking the amount of polymer film needed for reliable measurements (especially stress-strain relationships) into account.

\subsection{Morphology}

Using scanning electron microscopy (SEM), the final thickness of the films prior to the experimental procedures was determined and the surfaces of the films were examined. The films were immersed for $8 \mathrm{~h}$ in an aqueous solution of $2 \%$ tannic acid (Malinckrodt, USA) and 2\% arginine (Fluka, Switzerland), followed by immersion in a $2 \%$ aqueous $\mathrm{OsO}_{4}$ solution. The films were then washed, dehydrated in a graded ethanol series and critical point dried (Balzers type $11120)$. Subsequently, the films were sputter-coated (Balzers 07 120B) with gold and examined with the scanning electron microscope (Jeol 35C) operated at $15 \mathrm{kV}$. Specimens of films after 180 days immersion in a buffer (described in the following section) were also prepared and examined as described.

\subsection{Experimental procedures}

In vitro: strips of film measuring $40 \times 2 \mathrm{~mm}$ were immersed in a $0.1 \mathrm{M} \mathrm{Na}_{2} \mathrm{HPO}_{4} / \mathrm{KH}_{2} \mathrm{PO}_{4}$ buffer, $\mathrm{pH}$ 
7.4 , at $37^{\circ} \mathrm{C}\left( \pm 0.5^{\circ} \mathrm{C}\right)$. The maximum amount of polymer in $100 \mathrm{ml}$ buffer was $100 \mathrm{mg}$. $\mathrm{NaN}_{3}$ was added to a concentration of $0.03 \% \mathrm{w} / \mathrm{v}$ to prevent growth of micro-organisms. The buffer was replaced every 3 weeks. The $\mathrm{pH}$ never reached a value below 7.3. Evaluation using different tests was performed after $1,3,7,14,40,59,90,163$ and 180 days. The films were washed in distilled water for $6 \mathrm{~h}$ in order to remove buffer salts, air-dried for $16 \mathrm{~h}$ and subsequently dried in vacuum over $\mathrm{P}_{2} \mathrm{O}_{5}$ for $24 \mathrm{~h}$.

In vivo: all PLLA films were cut in strips of $15 \times 2 \mathrm{~mm}$ for implantation in the rat, taking into account the necessary distance between the films, in order to avoid interference in the tissue reaction. Prior to implantation, the strips of film, measuring $15 \times 2 \mathrm{~mm}$, were disinfected by immersion in $70 \%$ ethanol for $1 \mathrm{~min}$ and air-dried. The films were implanted subcutaneously in female $(\mathrm{AO} \times \mathrm{BN}) \mathrm{F}_{1}$ rats, weighing approximately $250 \mathrm{~g}$ and obtained from our own breeding facility. The rats were anaesthetized with ether, shaved on the back and disinfected locally with chlorohexidin $0.5 \%$ in $70 \%$ ethanol. Three incisions of approximately $1 \mathrm{~cm}$ each were made on the left side of the back, perpendicular to the midline and parallel to each other. Subsequently, subcutaneous pockets were made with blunt scissors. In each pocket, one strip of film was placed: a non-porous, a porous or a combi PLLA film. The wounds were closed using silk 3-0 (Ethicon) sutures. All rats had free access to standard rat food and water. All national rules regarding the use and care of laboratory animals have been observed. The rats were sacrificed after $1,3,7,14,40,90$ or 180 days. The samples were removed with excess surrounding tissue.

\subsection{Tensile strength and E-modulus}

Stress-strain curves (in vitro) were obtained using a Zwick tensile strength tester equipped with a $10 \mathrm{~N}$ load cell. At least four samples were tested for each immersion period. The samples were tested as removed from the buffer and were clamped mechanically. Samples from films as prepared were also tested. These results were used to calculate the initial tensile strength at $t=0$.

The tensile strength and E-modulus were calculated using the stress-strain data and surface area of the remaining polymer film, which were calculated using scanning electron micrographs, and the percentage of porosity as determined using morphometry on light microscopical sections. The normalized (to their initial $(t=0)$ value) tensile strength and E-modulus were also calculated.

\subsection{Mass}

The mass of the remaining polymer film (in vitro) was determined on a Mettler AE 200 balance with an accuracy of $0.05 \mathrm{mg}$. The procedure was carried out immediately after drying the strips of film over $\mathrm{P}_{2} \mathrm{O}_{5}$ in vacuum.
2.6. Relative polymer surface area in sections The relative polymer surface area (RPSA) in sections was determined after in vitro and in vivo procedures. After harvesting, samples were immediately fixed by immersion in a $0.1 \mathrm{M}$ Na-cacodylate buffer, $\mathrm{pH} 7.4$, containing $2 \%$ glutaraldehyde and $0.1 \mathrm{~m}$ sucrose, for at least $24 \mathrm{~h}$ at $4{ }^{\circ} \mathrm{C}$. After rinsing with buffer, the samples were dehydrated in a graded ethanol series. The samples were then embedded in a position which allowed sections to be cut perpendicular to the longitudinal axis of the polymer films. After embedding in glycolmethacrylate (GMA) (Technovit, Kulzer, Germany), sections of $3 \mu \mathrm{m}$ were cut on a Jung 1140 autocut microtome, using a D knife with a tungsten carbide cutting edge. The sections were mounted on glass and stained with toluidine blue and alkaline fuchsin [24].

The relative polymer surface area in sections (RPSA) was determined by morphometrical analysis using light microscopical sections and a Quantimet 520 (Cambridge Instruments) image analyser. The RPSA was defined as the ratio between the polymer surface area and measurement frame area. The boundaries of the measurement frame were set at the outer boundaries of the polymer surface area. The morphometrical analysis was performed on porous and combi films only, because the non-porous film was not eroded nor did it become porous, not even after an immersion or implantation period of 180 days. The RPSA of the non-porous film remained $100 \%$. For each implantation or immersion period ten measurements of the remaining polymer surface area (of at least two sections) were performed. The mean value and standard deviation were calculated from these ten values. All data were normalized to the initial value $(t=0)$.

\section{7. $\mathrm{Mw}, \mathrm{Mn}$ and polydispersity $(\mathrm{Mw} / \mathrm{Mn})$ ratio}

$\mathrm{Mw}$ and $\mathrm{Mn}$ (in vitro) were determined by gel permeation chromatography (GPC) at $20^{\circ} \mathrm{C}$ on a Waters Associates GPC apparatus using Waters Associates columns (bead size of $10^{4}, 10^{3}, 10^{2} \mathrm{~nm}$ ). A pre-column with a pore size of $50 \mathrm{~nm}$ was used. A Waters Associates R 403 differential refractometer was used as detector. A sample of 5 to $10 \mathrm{mg}$ was dissolved in $10 \mathrm{ml}$ chloroform and filtered (Spartan 13/20 filter, $0.45 \mu \mathrm{m}$ ). The injection volume per measurement was $200 \mu \mathrm{l}$. Chloroform was used as eluent at a flow rate of $2.0 \mathrm{ml} / \mathrm{min}$. The $\mathrm{Mw}, \mathrm{Mn}$ and polydispersity ratio were calculated using the calibration data of polystyrene standards of narrow molecular weight distribution dissolved in tetrahydrofuran (THF).

\subsection{Melting temperature and heat of fusion} Melting temperature, heat of fusion and thermograms (in vitro) were obtained using a Perkin Elmer DSC 7 Differential Scanning Calorimeter (DSC). A sample of 5 to $10 \mathrm{mg}$ was cooled to $-20^{\circ} \mathrm{C}$ at a rate of $100^{\circ} \mathrm{C} / \mathrm{min}$. After 10 minutes the sample was heated to $215^{\circ} \mathrm{C}$ at a rate of $10^{\circ} \mathrm{C} / \mathrm{min}$. 

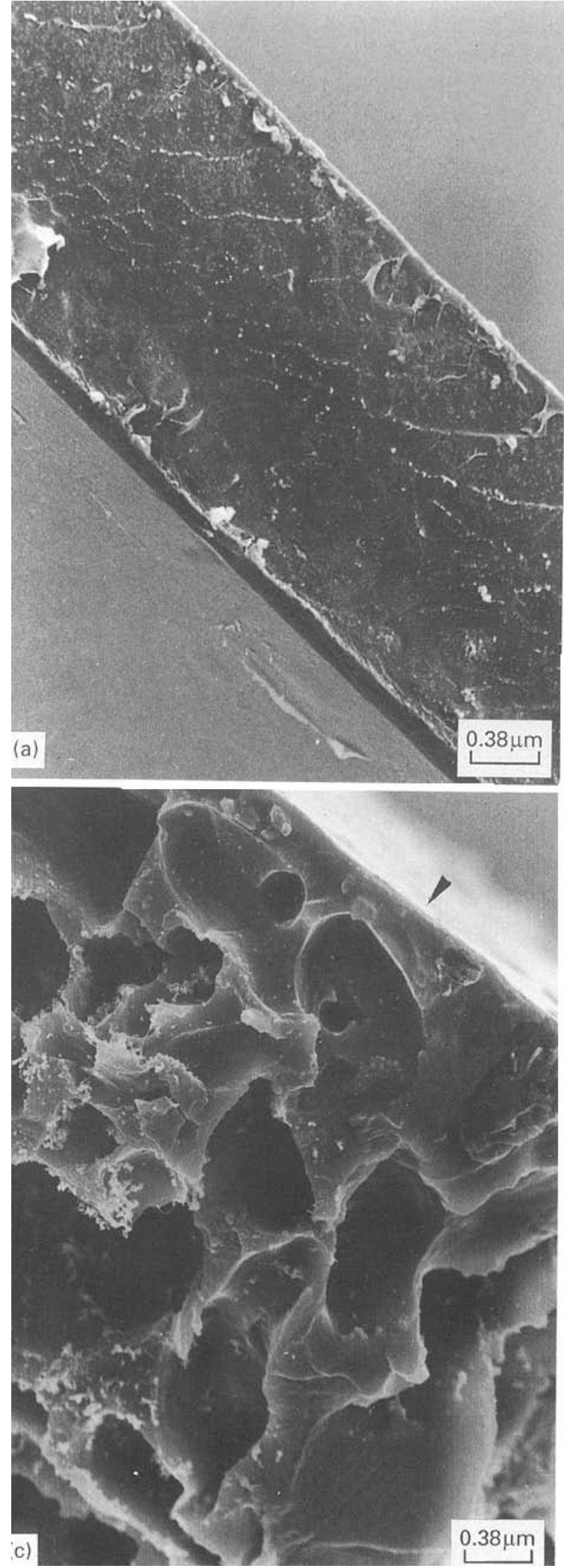

\section{Results}

\subsection{Morphology}

Using scanning electron microscopy the presence or absence of pores of the respective PLLA films was established and their thickness calculated: non-por-

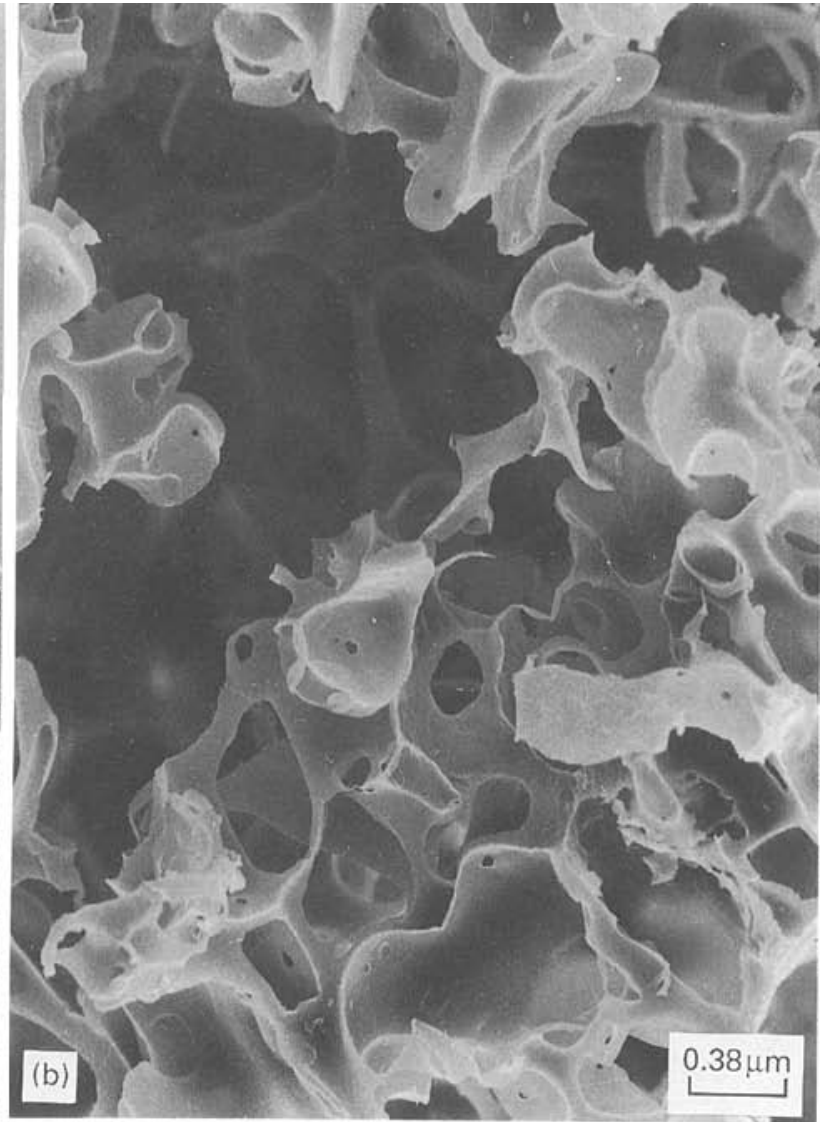

Figure 1 Scanning electron micrographs of a cross section of PLLA films: (a) non-porous; (b) porous; (c) combi (arrow head indicates the non-porous side). The thickness of the films is: non-porous, $33 \mu \mathrm{m}$, porous, $244 \mu \mathrm{m}$ and combi, $82 \mu \mathrm{m}$. The non-porous layer of the combi film was approximately $5 \mu \mathrm{m}$. The pore size of the porous film varied from approximately 1 to $150 \mu \mathrm{m}$ and of the combi film from 1 to $50 \mu \mathrm{m}$.

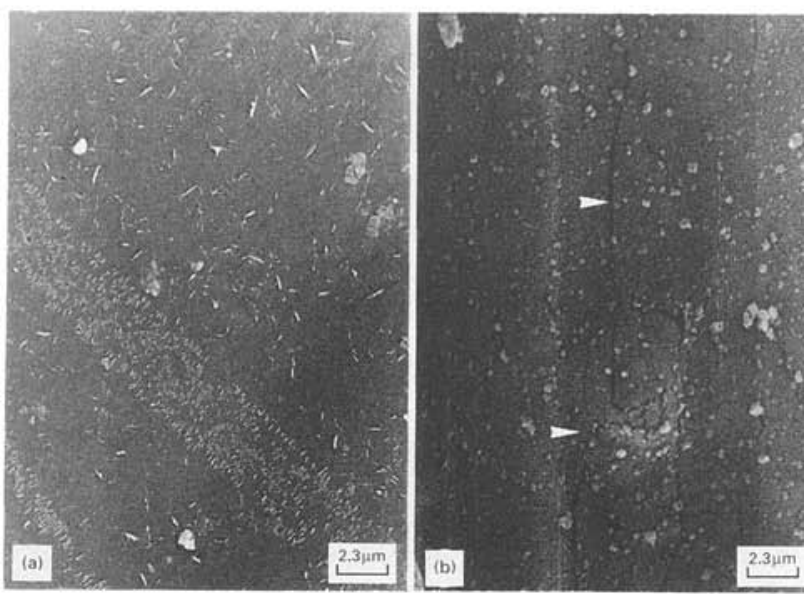

Figure 2 Scanning electron micrograph of non-porous PLLA film: (a) at day 0; (b) after 180 days immersion. Note the cracks (arrow heads).

ous, $33 \mu \mathrm{m}$ (Fig. 1a), porous, $244 \mu \mathrm{m}$ (Fig. 1b) and the combi film, $82 \mu \mathrm{m}$ (Fig. 1c). The non-porous layer of the combi film was approximately $5 \mu \mathrm{m}$. The pore size of the porous film varied from approximately 1 to $150 \mu \mathrm{m}$ and of the combi film from 1 to $50 \mu \mathrm{m}$. Cracks were observed on the surface of the non-porous film after immersion for 180 days (Fig. $2 a$ and 2b). The 
porous film and the porous part of the combi film did not show any change in morphology after a 180 day immersion period. However, the non-porous layer of the combi film was eroded at many places (Fig. 3a and $3 b)$.

\subsection{Tensile strength and E-modulus}

The results are presented in Fig. 4a-Fig. 4d. The tensile strength of all films decreased as a function of time (Fig. 4a). It was not possible to obtain stress-strain data at day 180, due to fragmentation. Fig. $4 \mathrm{c}$ shows
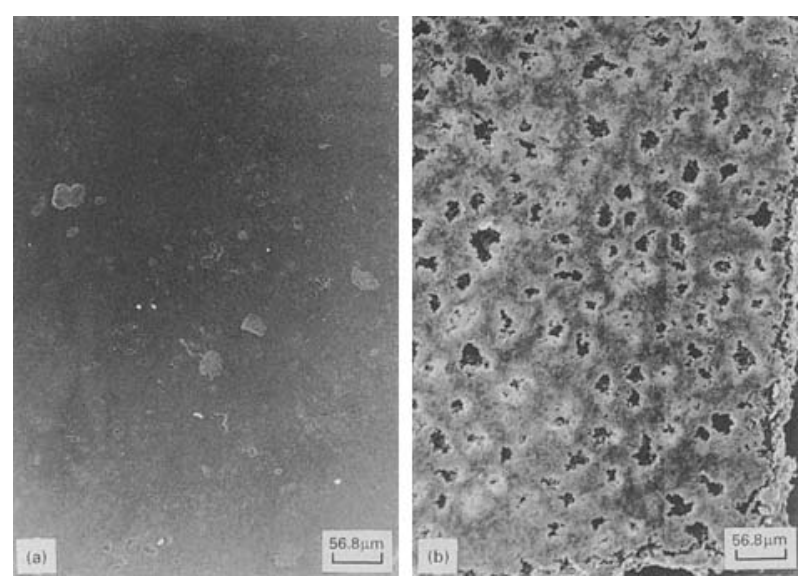

Figure 3 Scanning electron micrograph of the non-porous side of the PLLA combi film: (a) at day 0; (b) after 180 days immersion, demonstrating erosion of the thin non-porous layer.
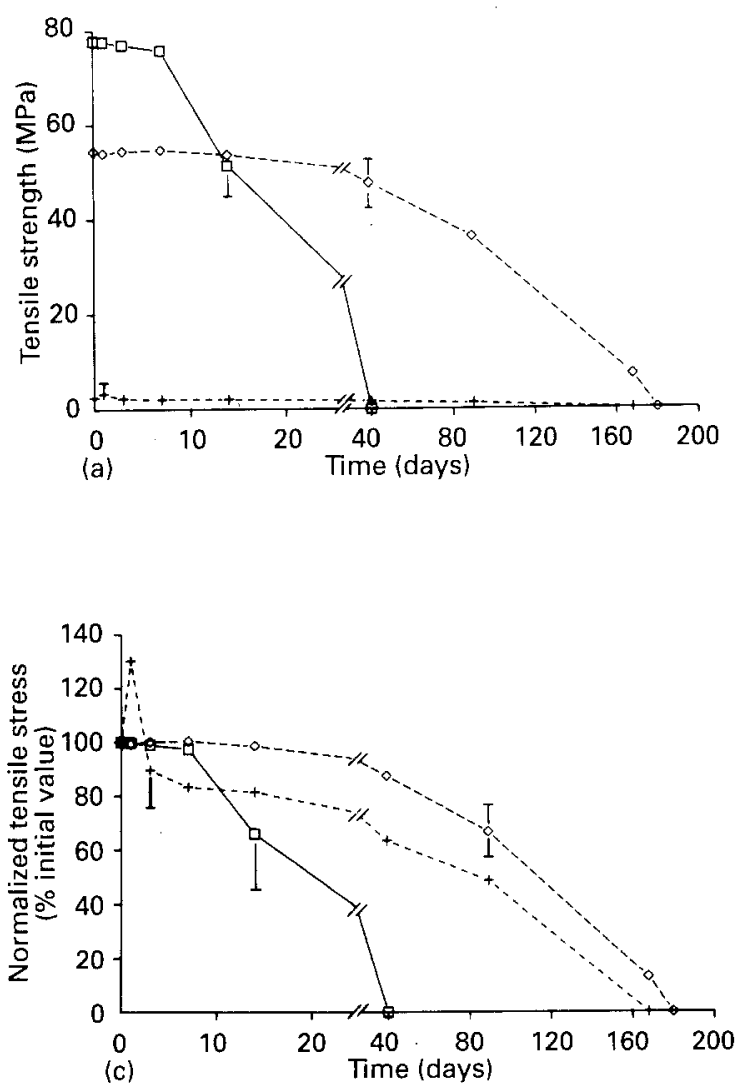

the rate of decrease in tensile strength (normalized to the initial values) of the PLLA films.

A large difference in initial tensile strength was found for the respective films (non-porous $78 \mathrm{MPa}$; porous $2.5 \mathrm{MPa}$; combi $54 \mathrm{MPa}$ ) (Fig. 4a). The tensile strength of the non-porous film decreased fastest. From day 40 on, it was not possible to obtain stress-strain data of the non-porous films due to the brittleness of the film, making clamping in the tensile strength tester impossible. This was also the case for the porous film from day 163 on and for the combi film at day 180 .

The E-modulus of the films (Fig. 4b) generally showed the same decreasing trend as the tensile strength. The differences in the rates of decrease are illustrated in Fig. 4d, which shows the normalized E-modulus of the respective PLLA films. The Emodulus of the non-porous film remained nearly constant up to day 7 and then decreased rapidly. The Emodulus of the combi film decreased more slowly. The E-modulus of the porous film shows a large variation and even tends to increase between day $14(24.6 \mathrm{MPa})$ and day $90(37.9 \mathrm{MPa})$. However, this increase was not significant ( $p=0.058$, independent $t$-test). From day 90 on, the rate of decrease in tensile strength was comparable to the rate of the combi film.

\subsection{Mass}

The mass after immersion in PBS for 180 days (Fig. 5) was $98.5 \%, 99.5 \%$ and $88 \%$ of the initial mass for the porous, combi and non-porous film, respectively.
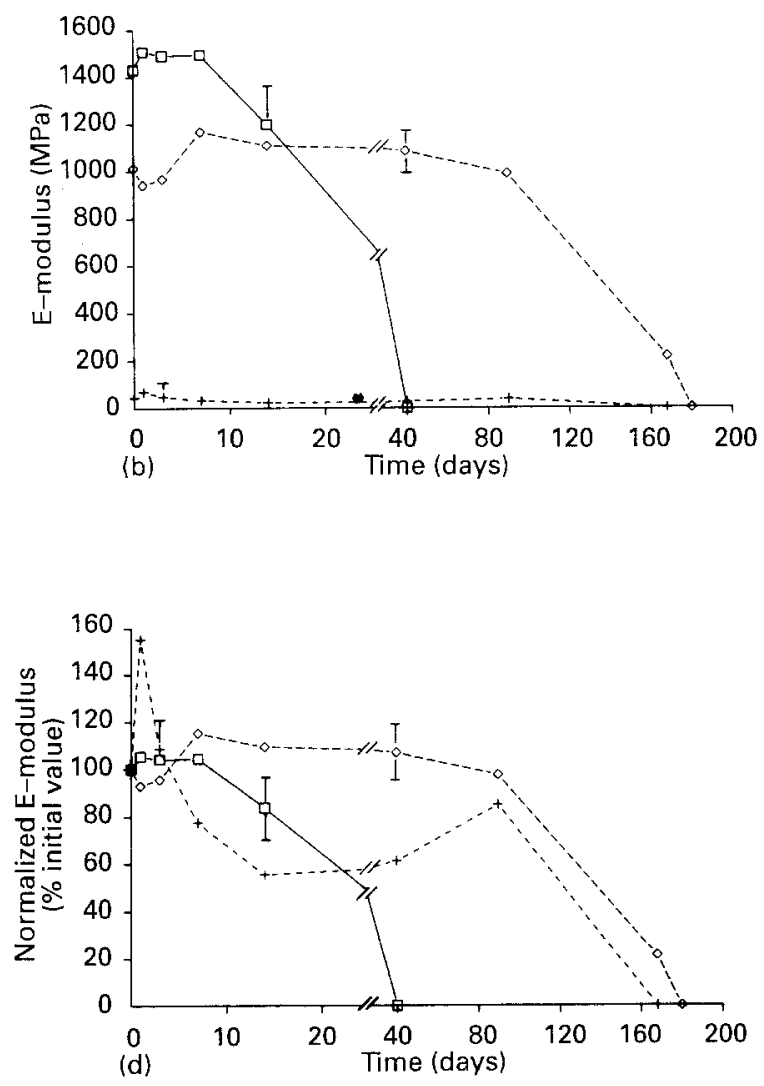

Figure 4 Tensile strength and E-modulus of the PLLA films as a function of immersion time. (a) tensile strength; (b) E-modulus; (c) normalized tensile strength; (d) normalized E-modulus. Symbols: - $\square$ - non-porous; - + - porous, - $\diamond$ - combi. Bars indicate the standard deviation. 


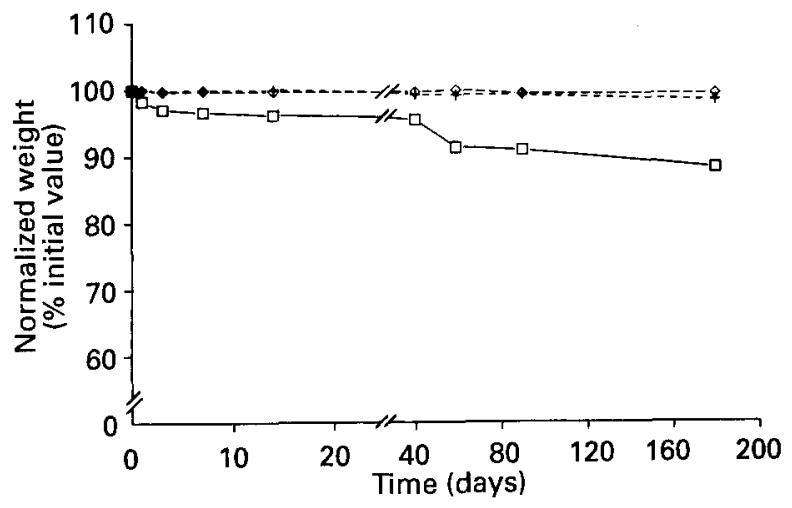

Figure 5 Normalized weight of the PLLA films as a function of immersion time. Symbols: - $\square$ - non-porous; - + - porous, - $\diamond$ combi. Standard deviation did not exceed $5 \%$.

\subsection{Remaining polymer surface area}

The results of the morphometrical analyses are presented in Fig. 6a (in vitro) and 6b (in vivo). The RPSA in vivo shows no significant decrease for the nonporous, the porous or the combi film. Also, no decrease was observed in vitro for the non-porous and porous film up till day 180 and for the combi film, up till day 90 . It was not possible to obtain the surface area of the combi film at day 180 , due to fragmentation.

During the in vivo experiment with the non-porous polymer film, no erosion or pore formation was observed. Moreover, after immersion in PBS (in vitro), it was not possible to carry the non-porous film through the embedding procedures for lightmicroscopy from
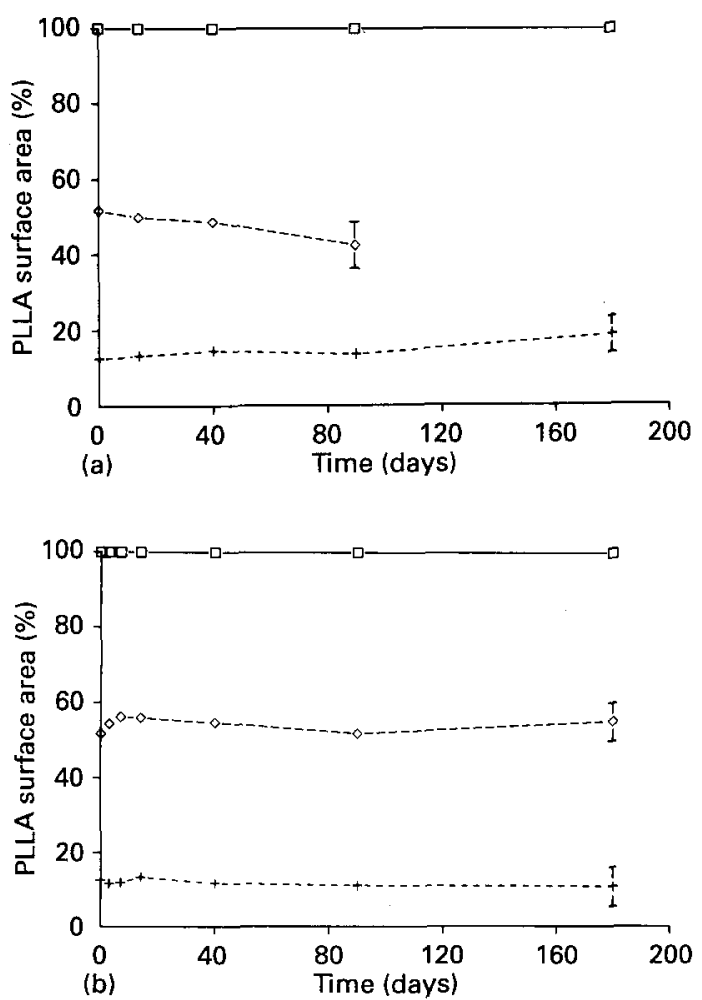

Figure 6 Remaining polymer surface area (RPSA) of the PLLA films in a light microscopical section: (a) in vitro: RPSA as a function of immersion time; (b) in vivo: RPSA as a function of implantation time. Symbols: - $\square$ - non-porous; - + - porous; - $\diamond$ - combi. Bars indicate the standard deviation. day 40 on, due to increased brittleness. The surface area of the remaining non-porous film remained $100 \%$ over the entire test period.

\section{5. $\mathrm{Mw}, \mathrm{Mn}$ and polydispersity $(\mathrm{Mw} / \mathrm{Mn})$ ratio}

The Mw (Fig. 7a) and Mn (Fig. 7b) decreased for all three films at approximately the same rate. From day 7 on, the porous film generally retained the highest $\mathrm{Mw}$ and $\mathrm{Mn}$. The initial $(t=0) \mathrm{Mw}$ of the combi film was the highest $(167000)$ and of the non-porous film the lowest $(98000$, porous 109000$)$. Before day 7 the curves of the porous and combi film showed large fluctuations for Mw (Fig. 7a). Thereafter, all values for $\mathrm{Mw}$ demonstrated a decreasing trend till the 180th day (Mw non-porous 24000 ; porous 60000 ; combi 29 000). The Mn curves roughly approximate the same trend as the Mw curves (Fig. 7b). The fluctuations of the values for the combi film are larger.
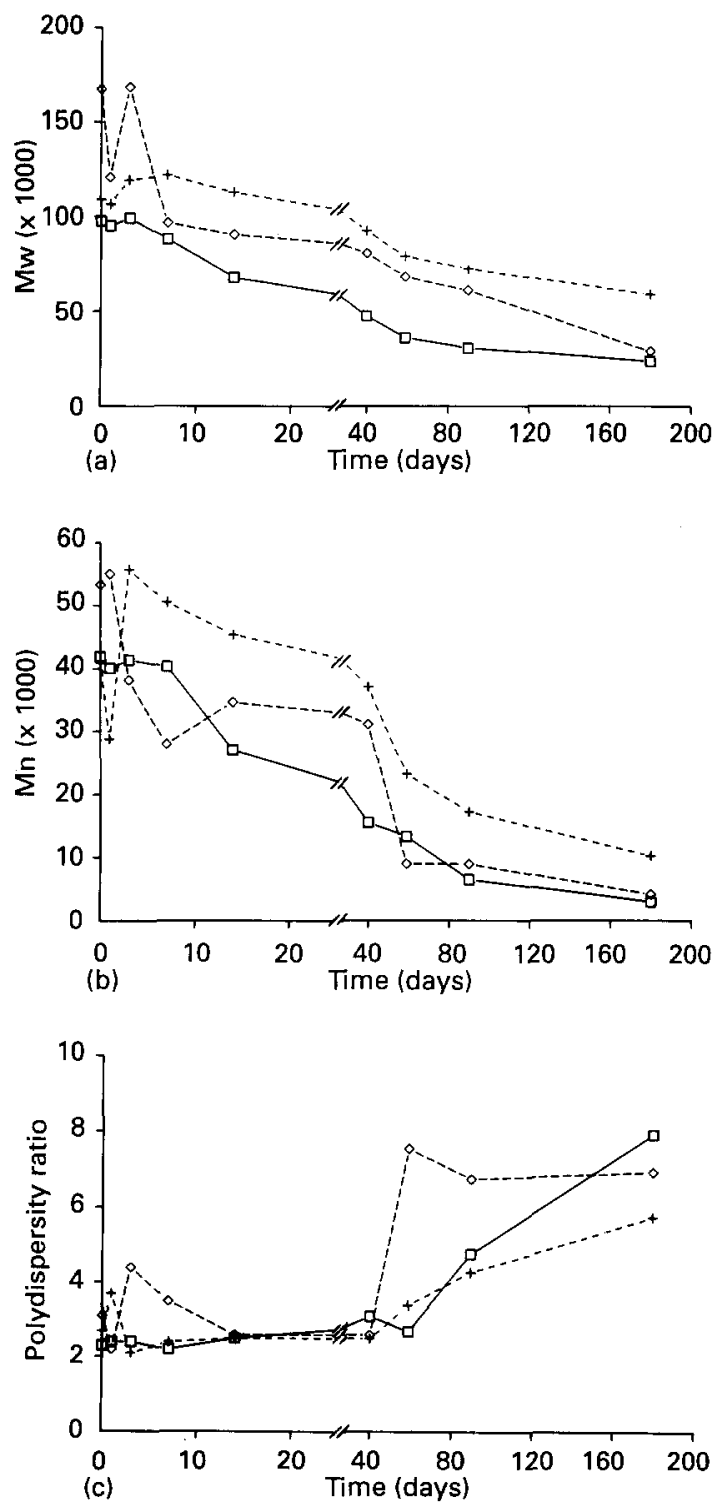

Figure 7 Molecular weight of the PLLA films as a function of immersion time. (a) $\mathrm{Mw}$; (b) $\mathrm{Mn}$; (c) polydispersity ratio ( $\mathrm{Mw} / \mathrm{Mn}$ ). Symbols: - $\square$ - non-porous; - + - porous; - $\diamond$ - combi. Standard deviation did not exceed $15 \%$. 

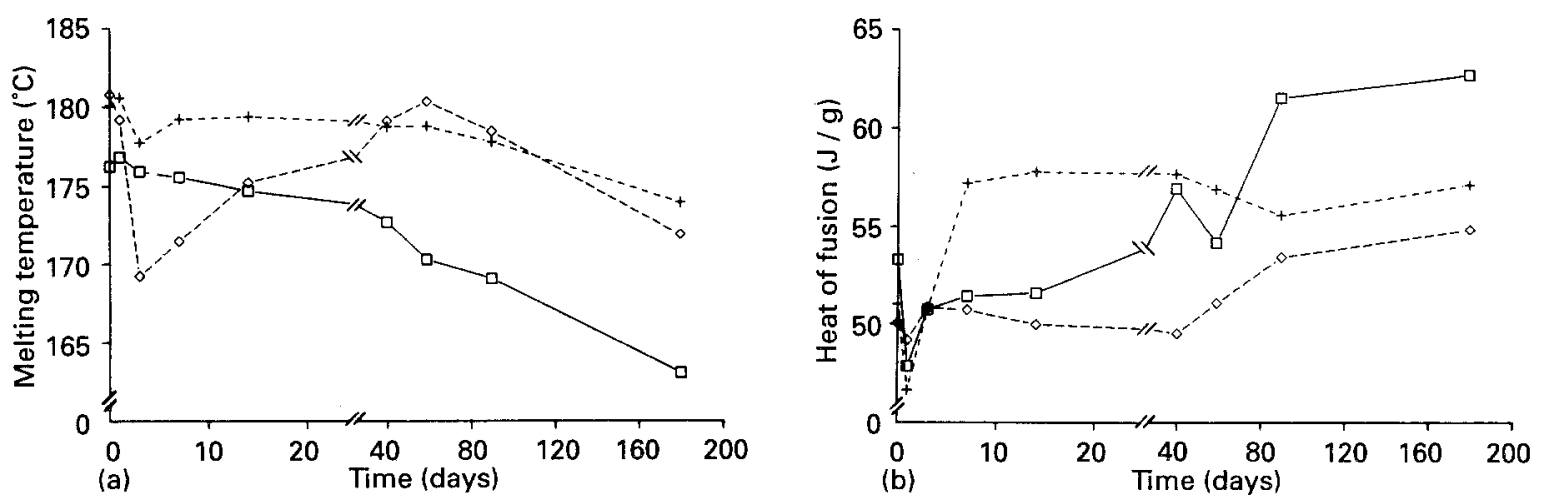

Figure 8 Melting temperature and heat of fusion of the PLLA films as a function of immersion time: (a) melting temperature $\left(T_{\mathrm{m}}\right)$; (b) heat of fusion. Symbols: - $\square$ - non-porous; - + - porous; - $\diamond$ - combi.
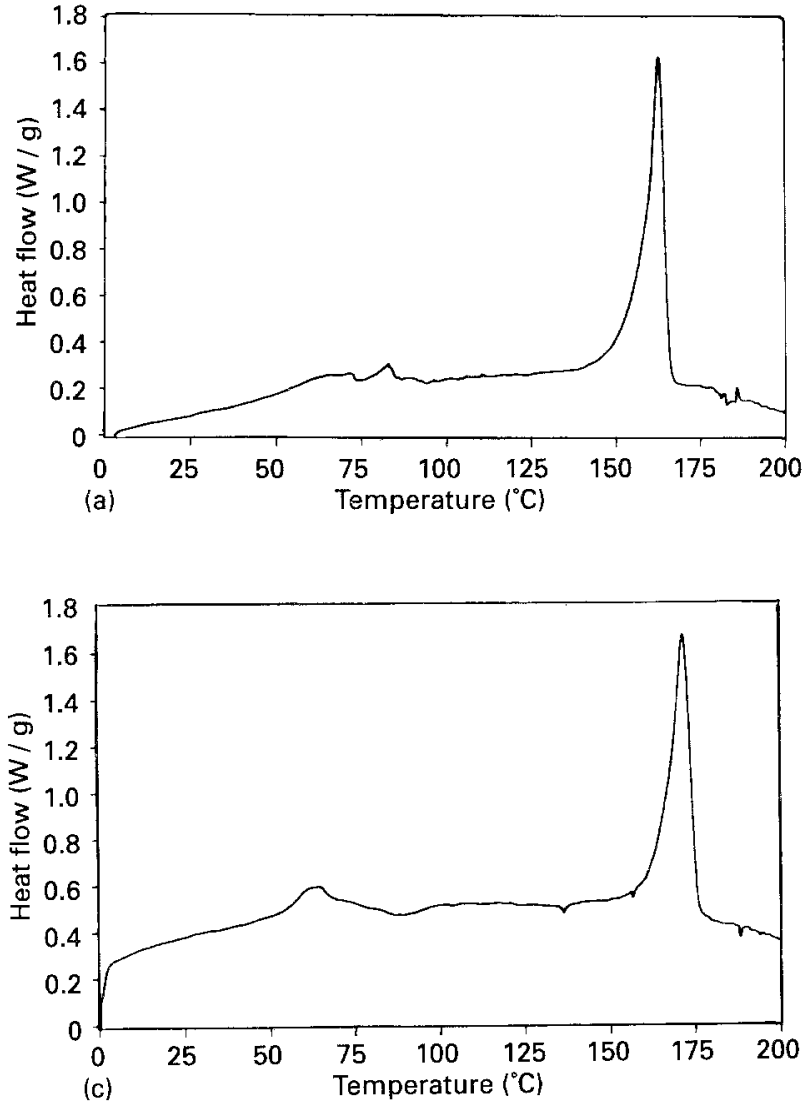

The polydispersity ratio (Fig. 7c) for all the films tends to rise with time. With slight variations all films show the same trend. At day 180 the $\mathrm{Mw} / \mathrm{Mn}$ ratio's are: non-porous 8 , porous 5.8 , combi 7 . This indicates that the non-porous film has the broadest molecular weight distribution at day 180 .

\subsection{Melting temperature and heat of fusion}

The melting temperature (Fig. 8a) decreased for all films from day 60 on, with a relatively large difference between the porous and combi film on one side and the non-porous film on the other. Fluctuations in melting temperature were observed for the porous film until day 14 and for the combi film until day 59 . The melting temperature of the non-porous film only showed a small fluctuation until day 7. From day 14

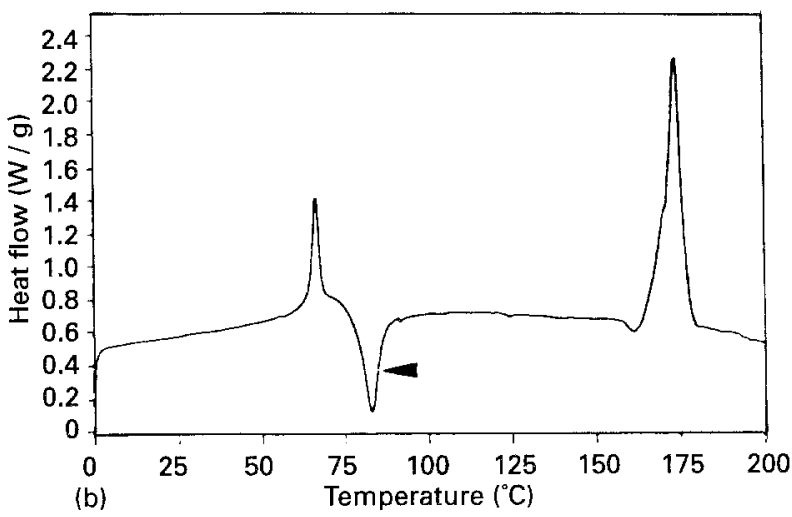

Figure 9 Thermograms of the PLLA films, adjusted for weight (heat flow as a function of time), after 180 days of immersion in PBS: (a) non-porous; (b) porous; (c) combi. Note the exothermal peak (arrowhead) for the porous polymer, which may indicate recrystallization of the amorphous regions.

until day 180 the melting temperature of the nonporous film was lowest ( $T_{\mathrm{m}}$ on day 180: non-porous $163.1^{\circ} \mathrm{C}$; porous $174.1{ }^{\circ} \mathrm{C}$; combi $172.0^{\circ} \mathrm{C}$ ).

The general trend for heat of fusion (Fig. 8b) showed an increase with time (on day 180: non-porous $62.8 \mathrm{~J} / \mathrm{g}$; porous $57.2 \mathrm{~J} / \mathrm{g}$, combi $54.9 \mathrm{~J} / \mathrm{g}$ ). The heat flow on the thermal analysis plots showed an exothermic peak between the glass transition and melting temperature. This exothermic peak was only clearly distinguishable for the porous polymer (Fig. 9).

\section{Discussion}

The difference in the initial values for tensile strength is probably caused by the difference in the morphology of the films. It is difficult to compare the tensile strength of films having a different morphology without additional measurements [22]. When comparing the films, the normalized tensile strength and E-modulus are more informative for the degradation rate. The tensile strength and E-modulus of the non-porous film decrease faster than the porous and combi film, indicating a higher degradation rate for the non-porous film.

The results of the mass measurements indicate that most of the core of the PLLA films is retained during 
the in vitro experiment. The higher decrease in mass of the non-porous film is consistent with its higher decrease in tensile strength. However, decrease in tensile strength cannot be attributed to the loss of mass only, because the tensile strength and E-modulus of the non-porous and combi film decreased without a significant loss of mass.

The RPSA, which was determined only for the porous and the non-porous polymer film, did not decrease significantly, either in vitro or in vivo. However, these results must be interpreted with some caution, because RPSA measurements cannot detect release of small amounts of degradation products from the core of the polymer film. The loss of mass of the non-porous film could not be detected with RPSA measurements since there was no detectable loss of surface area in the cross-sections of the PLLA film. There was also no indication of measurable surface erosion, such as increasing surface roughness and/or decreasing thickness of the non-porous film. However, this method might be useful in quantifying the later stages of degradation and the resorption process in vivo, when weight measurement has become practically impossible. The results indicate that in vitro, the core of the PLLA films remains largely intact till day 180 and that in vivo, there was no resorption of large amounts of polymer. These findings support the results of the weight measurements.

The results of the molecular weight measurements indicate a higher degradation rate for the non-porous film than the combi and porous film; the latter having the lowest degradation rate. The decrease of $\mathrm{Mw}$ and $\mathrm{Mn}$ is obvious for all three types of film, although results obtained with GPC must be interpreted with caution when low molecular weight polymers, resulting from degradation processes are examined [20, 21]. Therefore, the differences between the films may not be significant, but the higher $\mathrm{Mw}$ and $\mathrm{Mn}$ of the porous film compared to the non-porous film from day 7 till the end of the experiment at day 180 , is very suggestive. The initial $\mathrm{Mw}$ and $\mathrm{Mn}$ of the different films are not equal (Fig. 4a). A possible explanation may be the washing-out of a larger part of the low molecular weight fraction into the media of the extra rinsing step, in order to remove the sodium citrate, of the films with a porous component: therefore a higher $\mathrm{Mw}$ and Mn was measured. However, it can be expected that washing-out of low molecular weight fractions probably also occurs during immersion of the non-porous film in the buffer. As a consequence, it can be expected that the difference in $\mathrm{Mw}$ and $\mathrm{Mn}$ between the films would disappear in the course of the experiment. This was not the case, indicating another process having an effect on $\mathrm{Mw}$ and $\mathrm{Mn}$. At day 180 the $\mathrm{Mw}$ and $\mathrm{Mn}$ values of the combi film tend to approach those of the non-porous film. This trend corresponds with the erosion of the thin non-porous layer of the combi film as observed with SEM: the combi film was becoming a porous one. Also, the $\mathrm{Mw}$ and $\mathrm{Mn}$ show a lot of fluctuations during the first 2 weeks of the experiment. These fluctuations might be caused by two phenomena having an opposite effect on $\mathrm{Mw}$ and $\mathrm{Mn}$ : washing-out of low molecular weight fractions and molecular chain fragmentation. However, as stated earlier, this remains hypothetical, as the amount of polymer compared to the amount of buffer in which they were placed did not allow for a analysis using GPC.

The polydispersity ratio fluctuates considerably, but from day 90 it appears that the polydispersity ratio of the non-porous film is increasing at a higher rate, indicating an increase in the number of low molecular weight fractions as compared to the porous and combi film. At day 180 , the non-porous film consists of more low molecular weight fractions as compared to the porous and combi one, which is also consistent with a higher degradation rate of the nonporous film.

The melting temperature of non-crosslinked polymers primarily depends on the length of the molecular chain [25]. The trends in melting temperature are consistent with the trends in $\mathrm{Mw}, \mathrm{Mn}$ and polydispersity ratio, which indicate a higher degradation rate of non-porous film than porous and combi film.

The heat of fusion values indicate an increase of crystallinity for all polymers during immersion in PBS. However, these values are to be considered carefully, because during heating, recrystallization may be induced [25]. The thermogram of the porous film shows a larger exothermal peak between the glass transition temperature and melting temperature when compared to the non-porous and combi film (Fig. 9). Therefore, the heat of fusion data for porous films cannot be used to draw conclusions on crystallinity. It can only be concluded that the crystallinity of the nonporous film (which shows a smaller recrystallization peak in the thermograms at 180 days) is the highest of the three. This can be an indication of the presence of a larger amount of smaller molecules than in the porous and combi film, because crystalline regions are formed more easily by relatively small molecules. These results are consistent with the results of tensile strength, weight, molecular weight, and melting temperature measurements, all indicating that non-porous PLLA degrades faster than porous and combi PLLA film.

Hydrolysis of ester bonds is the major mechanism of PLLA degradation [26]. Mechanical stress may enhance the degradation process [27]. Radiation (UV, IR) or heat are not expected to contribute very much to the degradation of polyesters in vivo $[10,11]$. The role of enzymes in the degradation process in vivo is not clear [12-14]. Most enzymes in eukaryotic cells are substrate specific. Therefore, a specific threedimensional structure of the substrate (polymer) is required to reach the active centre of the enzyme. This is not likely at $37^{\circ} \mathrm{C}$ under physiologic enzyme concentrations. The probability is even smaller for the crystalline parts of the polymer (film). However, enhancement of the degradation rate in vitro by enzymes was observed for some polymer/enzyme systems [12-14]. The role of enzymes may be larger when smaller molecules have been formed by other degradation mechanisms (hydrolysis). This was not investigated in the experiments described in this paper.

Degradation of polyesters, such as PLLA, primarily takes place in the amorphous part of the polymer film 
$[15,28]$. This may explain the increasing crystallinity, also observed by other authors [28]. However, in order to explain the difference in degradation rate between the non-porous and porous PLLA film, one must assume other processes taking place during degradation. Vert et al., using different polyester "plates" of $2 \times 17 \times 20 \mathrm{~mm}$, observed the formation of a polymer layer around the core of the polymer film, largely preventing degradation products (e.g. oligomers) released in the core, to diffuse freely to the aqueous environment. The chemical reactive endgroups of the accumulated oligomers in the core then enhance the degradation (autocatalytic) process [15-17]. The nonporous polymer film is more susceptible to this form of degradation, probably because a larger inner compartment can be formed than in the porous and combi film. The surface/volume ratio of the latter two are probably larger than the cut off value of the polymer surface/volume ratio regarding this effect.

However, other mechanisms are also possible. There is less flow of the aqueous media in pores of the porous polymer film. Therefore, the concentration of oligomers might be higher in the pores, enhancing degradation. Nevertheless, this mechanism apparently has less effect than the mechanism(s) leading to a higher degradation rate of the non-porous PLLA film.

In summary, it can be stated that data from the physico-chemical, mechanical and cell biological measurements are needed to obtain a comprehensive picture of the processes leading to the differences in the degradation rate of PLLA films having a different porosity (morphology). It is concluded that non-porous PLLA degrades faster than porous PLLA. Thus, in our model, porosity is an important determinant of the degradation rate of PLLA films.

\section{Acknowledgements}

The authors gratefully acknowledge the advice, assistance and support of: E. H. Blaauw, D. Kalicharan, I. Stokroos, J. Ruben, R. O. Leonora, A. J. Oostenbrink, H. Slagter, P. in het Veld, D. Huizinga, H. Meiborg and P. van der Sijde.

\section{References}

1. B. D. RATNER, in "Comprehensive polymer science", edited by S. L. Aggarwal (Pergamon, Oxford, 1989) p. 201.

2. J. E. DAVIES, in "Surface characterization of biomaterials", edited by B. D. Ratner (Elsevier Science Publishers B.V., Amsterdam, 1988) p. 219.

3. R. A. WHITE, F. M. HIROSE, R. W. SPROAT, R. S. LAWRENCE and R. J. NELSON, Biomaterials 2 (1981) 171.
4. B. CHEHROUDi, T. R. L. GOULD and D. M. BRUNETTE, J. Biomed. Mater. Res. 24 (1990) 1203.

5. B, F. MATLAGA, L. P. YASENCHAK and T. N. SALTHOUSE, ibid. 10 (1976) 391.

6. D. BAKKER, C. A. V. BLITTERSWIJK, S. C. HESSELING, J. J. GROTE and W. T. DAEMS, Biomaterials 9 (1988) 14.

7. P. B. WACHEM, M. J. A. V. LUYN, P. NIEUWENHUIS, H. K. KOERTEN, L. OLDE DAMINK, H. TEN HOOPEN and J. FEIJEN, ibid. 12 (1991) 215.

8. J. M. SCHAKENRAAD, P. NIEUWENHUIS, I. MOLENAAR, J. HELDER, P. J. DIJKSTRA and J. FEIJEN, $J$. Biomed. Mater. Res. 23 (1989) 1271.

9. J. M. SCHAKENRAAD, J, A. OOSTERBAAN, P. NIEUWENHUIS, I. MOLENAAR, J. OLIJSLAGER, W. POTMAN, M. J. D. EENINK and J. FEIJEN, Biomaterials 9 (1988) 116.

10. S. J. HUANG, in "Comprehensive polymer science" edited by G. C. Eastmond, A. Ledwith, S. Russo and P. Sigwald (Pergamon, Oxford, 1989) p. 597.

11. D. F. WILLIAMS, in "Comprehensive polymer science" edited by G. C. Eastmond, A. Ledwith, S. Russo and P. Sigwald (Pergamon, Oxford, 1989) p. 607.

12. Idem., Engineering in Medicine 10 (1981) 5.

13. D. F. WILLIAMS and E. MORT, J. Bioeng. 1 (1977) 231.

14. R. SMITH, C. OLIVER and D. F. WILLIAMS, J. Biomed. Mater. Res. 21 (1987) 991.

15. SU MING LI, H. GARREAU and M. VERT, J. Mat. Sci.: Mater. Med. 1 (1990) 123.

16. Idem., ibid. 1 (1990) 131.

17. Idem., ibid. 1 (1990) 198.

18. J. W. LEENSLAG, A. J. PENNINGS, R. R. M. BOS, F. R. ROZEMA and G. BOERING, Biomaterials 8 (1987) 70.

19. D. K. GILDING and A. M. REED, Polymer 20 (1979) 1459.

20. J. A. V. D. BERG and J. SCHUIJER, in "Macromolecular biomaterials" edited by G. W. Hastings and P. Ducheyne (CRC Press, Boca Raton, 1984) p. 21.

21. J. V. DAWKINS, in "Comprehensive polymer science", edited by C. Booth and C. Price (Pergamon, Oxford, 1989) p. 231.

22. R. J. YOUNG, in "Comprehensive polymer science", edited by C. Booth and C. Price (Pergamon, Oxford, 1989) p. 511.

23. A. SCHINDLER and D. HARPER, J. Polymer Sci. 17 (1979) 2593.

24. E. H. BLAAUW, M. F. JONKMAN and P. O. GERRITS, Acta Morphol. Neerl.-Scand. 25 (1987) 167.

25. M. J. RICHARDSON, in "Comprehensive polymer science", edited by C. Booth and C. Price (Pergamon, Oxford, 1989) p. 867.

26. K. JAMSHIDI, S.-H. HYON, T. NAKAMURA, Y. IKADA, Y. SHIMIZU and Y, TERAMATSU, in "Advances in biomaterials. Biological and biomechanical performance of biomaterials" edited by P. Christel, A. Meunier and A. C. J. Lee (Elsevier Science Publishers BV, Amsterdam, 1986) p. 227.

27. J. SOHMA, in "Comprehensive polymer science" edited by G. C. Eastmond, A. Ledwith, S. Russo and P. Sigwald (Pergamon, Oxford, 1989) p. 621.

28. J. W. LEENSLAG, A. J. PENNINGS, R. R. M. BOS, F. R. ROZEMA and G. BOERING, Biomaterials 8 (1987) 311.

Received 15 December 1992

and accepted 21 September 1993 